\title{
Prevalence of Gastrointestinal Parasite on Cats in Shelter East Surabaya
}

\section{Prevalensi Parasit Saluran Pencernaan pada Kucing yang Terdapat di Shelter Surabaya Timur}

\author{
${ }^{1)}$ Akbar Wijaya Putra Purnama, ${ }^{2)}$ Lucia Tri Suwanti, ${ }^{3)}$ Hani Plumeriastuti, ${ }^{2)}$ Endang Suprihati, \\ ${ }^{2)}$ Kusnoto, ${ }^{2)}$ Agus Sunarso \\ ${ }^{1}$ Student, Faculty of Veterinary Medicine, Universitas Airlangga \\ ${ }^{2)}$ Department of Veterinary Parasitology, Faculty of Veterinary Medicine, Universitas Airlangga \\ ${ }^{3}$ Department of Veterinary Pathology, Faculty of Veterinary Medicine, Universitas Airlangga \\ Received: 02-08-2019, Accepted: 09-08-2019, Published Online: 16-08-2019
}

\begin{abstract}
The purpose of this study was to determine the prevalence of gastrointesatinal parasites in cats at Surabaya shelter. Eighty two samples of cat feces used in this study were taken from Griya satwa shelter and Kiro cat shelter. Feces samples were examined using the native, sedimentation and floating methods. Feces samples gastrointestinal parasite were identified by using a microscope with 40ox and 10oox magnifications. Faces samples that are diagnosed positively if there is at least one of the three methods. Feces samples has observed, obtained prevalence rate of $43.9 \%$ or 36 positive samples from eighty two samples. The results of chi square analysis showed that $\mathrm{p}>0.05$, which showed that the parasites taken in the two shelters had clear differences in the prevalence of the gastrointestinal tract parasites. The parasites observed were Isospora sp., Ancylostoma sp., Toxocara cati and Toxocara leonina.
\end{abstract}

\section{Keyword: prevalence, gastrointestinal parasite, cat, shelter}

\section{Pendahuluan}

Kucing merupakan salah satu hewan yang sering dijumpai di lingkungan masyarakat baik di perkotaan maupun di pedesaan (Sulaiman, 2010). Menurut Madyantari (2016), populasi kucing meningkat dengan kelahiran setiap harinya lebih dari 50.0oo, dari populasi kucing tersebut hanya $1 / 5$ yang dipelihara sedangkan sisanya hidup secara liar dan 6-8 juta kucing masuk penampungan hewan (shelter). Populasi kucing yang hidup liar menimbulkan masalah di lingkungan, oleh sebab itu masyarakat membangun tempat penampungan hewan atau shelter.

Shelter berfungsi sebagai tempat melindungi dan menyelamatkan hewan yang dibuang dan ditelantarkan (Tradana, 2011). Shelter yang didirikan masyarakat di Indonesia umumnya bertempat di kediaman masingmasing dengan sanitasi dan manajemen yang kurang baik. Sanitasi dan manajemen yang kurang baik mengakibatkan meningkatnya bahaya penularan penyakit baik dari hewan ke hewan atau dari hewan ke manusia (Sucitrayani dkk., 2014).

Kejadian penyakit pada kucing yang sering terjadi adalah infeksi parasit saluran pencer- naan (Pabundu, 2007). Berbagai faktor yang mempengaruhi peningkatan penyakit saluran pencernaan pada kucing di shelter adalah kucing liar yang baru memasuki shelter, lingkungan shelter yang kotor, manajemen kandang yang kurang baik, pemberian obat cacing yang tidak teratur, kurangnya perhatian pemilik kepada hewan, dan populasi kucing yang terlalu banyak (Hajipour dkk., 2016). Menurut Raza dkk. (2018) pengendalian parasit saluran pencernaan di shelter dapat dilakukan dengan memperbaiki manajemen shelter seperti selalu menjaga kebersihan kandang, membersihkan feses yang terdapat di kandang maupun lingkungan dengan teratur dan disinfeksi kandang maupun lingkungan secara berkala.

Parasit saluran pencernaan pada kucing dibagi menjadi dua yaitu protozoa dan cacing. Protozoa yang menyerang saluran pencernaan pada kucing antara lain: Eimeria sp., Isospora sp., Entamoeba sp., Toxoplasma sp., Giardia sp., Trichomonas sp. dan Cryptosporidium sp. (Levine, 1995). Cacing yang dapat menyebabkan saluran pencernaan pada kucing antara lain: Toxocara cati, Ancylostoma sp., Strongyloides sp., Dypilidium cacninum, 
Diphylobothrium latum, Heterophyes heterophyes (Bowman dkk., 2002). Penelitian yang dilakukan oleh Pereira dkk. (2017) di shelter Rio de Janeiro, Brazil ditemukan parasit yang menginfeksi saluran pencernaan yaitu Toxocara cati, Dypilidiun cacninum, Cystoisospora felis dan Cystoisospora rivolta.

Menurut Pereira dkk (2015) prevalensi parasit saluran pencernaan yang diambil di shelter Rio de Janeiro memiliki angka prevalensi sebesar 49,5\%, sedangkan pada penelitian Gracenea dkk. (2009) di shelter Barcelona, Spanyol memiliki angka prevalensi parasit saluran pencernaan sebesar $34,0 \%$. Laporan penelitian di Indonesia mengenai prevalensi parasit saluran pencernaan pada hewan kecil terutama kucing masih sedikit (Pabundu, 2007), sedangkan di Surabaya belum ada laporan tentang prevalensi parasit saluran pencernaan kucing di shelter. Berdasarkan uraian tersebut, maka penelitian tentang prevalensi parasit saluran pencernaan kucing di shelter Surabaya perlu dilakukan.

\section{Metode penelitian}

Penelitian ini dilakukan di Laboratorium Parasit Fakultas Kedokteran Hewan Universitas Airlangga. Pengambilan sampel feses dilakukan di 2 selther Surabaya Timur yaitu shelter Griya Satwa dan Kiro Cat. Alat-alat yang digunakan dalam penelitian ini adalah pot salep sebagai tempat sampel feses, kertas label untuk melabeli dan memberi keterangan sampel yang sudah diambil.

Alat-alat yang digunakan dalam penelitian ini adalah lidi atau gelas pengaduk, saringan teh, pipet, kaca obyek, kaca penutup, tabung sentrifus, alat sentrifus, rak tabung, sarung tangan dan masker. Bahan yang digunakan dalam penelitian ini berupa sampel feses kucing, larutan formalin 10\%, kalium dikromat, garam jenuh, gula jenuh dan air PDAM.

Dalam penelitian ini feses yang digunakan adalah feses segar. Feses diambil secukupnya lalu dimasukkan ke dalam plastic/pot dan diberi formalin $10 \%$ dan kalium dikromat. Setiap plastic/pot diberi label atau penanda nomor sampel yang disesuaikan dengan pendataan sampel saat waktu pengambilan. Sampel feses lalu dibawa ke laboratorium untuk diperiksa (Mumpuni dkk., 2016). Jika dalam pemeriksaan tidak ditemukan stadium protozoa namun belum bisa diindentifikasi, maka sampel tersebut didiamkan selama satu sampai tiga hari agar terjadi proses sporulasi yang bertujuan untuk mempermudah identifikasi bentuk kista dan ookista protozoa (Afiyah, 2015).

Sampel yang telah terkumpul selanjutnya diperiksa di Laboratorium Parasitologi Fakultas Kedokteran Hewan Universitas Airlangga. Metode yang digunakan untuk pemeriksaan feses ini dibagi menjadi dua. Untuk pemeriksaan parasit jenis protozoa digunakan metode metode natif, metode sedimentasi dan metode apung. Sedangkan pemeriksaan parasit jenis cacing digunakan metode natif, sadimen dan apung (Mumpuni dkk., 2016).

Dalam metode natif, memerlukan gelas pengaduk yang kecil, air, object glass dan cover glass. Feses diambil dengan ujung gelas pengaduk lalu dioleskan pada object glass dan ditambah satu atau dua tetes air, diratakan dan ditutup dengan cover glass. Kemudian dilakukan pemeriksaan di bawah mikroskop dengan pembesaran 10ox (Mumpuni dkk., 2016).

Feses sebanyak kira-kira 5 gram dimasukkan ke dalam plastic lalu ditambahkan air dengan perbandingan 1 bagian feses dengan 10 bagian air lalu disaring dan dimasukkan dalam tabung sentrifus. Suspensi disentrifus dengan kecepatan 1500 rpm selama 2-5 menit. Supernatan dibuang, endapan ditambah air dan disentrifus lagi selama 2-5 menit. Proses ini dilakukan beberapa kali sampai supernatant jenuh. Supernatan yang telah jernih, dibuang airnya dan disisakan sedikit, lalu endapan diaduk dan diambil sedikit dengan pipet Pasteur dan di teteskan pada object glass dan tutup dengan cover glass. Selanjutnya dilakukan pemeriksaan mikroskop dengan pembesaran 10ox (Mumpuni dkk., 2016).

Sisa supernatan yang sudah jernih dari metode sedimentasi ditambahkan larutan gula jenuh sampai $1 \mathrm{~cm}$ dari mulut tabung lalu disentrifus dengan cara yang sama. Tabung yang telah di sentrifus diletakkan pad arak tabung dan pelan-pelan ditetesi dengan larutan gula jenuh sampai cairan terlihat cembung pada mulut tabung sentrifus. Lalu meletakkan cover glass pelan-pelan diatas tabung sentrifus lalu dibiarkan 1-2 menit. Mengambil dan meletakkan cover glass diatas object glass, kemudian dilakukan pemeriksaan di bawah mikroskop dengan pembesaran 10ox pada cacing dan 40x pada protozoa (;Mumpuni dkk., 2016 dan Nealma, 2013). 


\section{Analisis data}

Sampel yang positif kemudian dihitung prevalensinya dengan menggunakan rumus prevalensi (Murtidjo, 1994) dapat dihitung dengan cara sebagai berikut. Prevalensi dihitung berdasarkan sampel +/ total sampel dinyatakan dalam \%. Data yang diperoleh dianalisis menggunakan chi square.

\section{Hasil dan Pembahasan \\ Prevalensi Parasit Saluran Pencernaan pada Kucing yang Terdapat di Shelter Surabaya Timur}

Prevalensi parasit saluran pencernaan pada kucing yang terdapat di shelter Surabaya Timur dapat dilihat pada Tabel 1. didapatkan angka prevalensi sebesar 43,9\% atau 36 sampel positif dari 82 sampel yang diamati. Berbeda pada penelitian yang dilakukan oleh Joffe dkk. (2011) di shelter kota Calgary, Canada menggunakan 153 sampel feses kucing didapatkan prevalensi parasit saluran pencernaan sebesar 55\%. Adanya perbedaan angka prevalensi dengan penelitian yang dilakukan oleh Joffe dkk. (2011) kemungkinan disebabkan dari segi geografis negara yang berbeda. Penelitian Joffe dkk. (2011) dilakukan di Calgary yang merupakan kota dari negara Canada, negara Canada memiliki rata-rata kelembapan 58\% dan memiliki suhu rata-rata $6{ }^{\circ} \mathrm{C}$ dengan suhu minimum -8 o $C$. Berbeda dengan Calgary, Surabaya memiliki suhu rata-rata $27^{\circ} \mathrm{C}$ dengan suhu minimum $23^{\circ} \mathrm{C}$. Hal tersebut dapat menjadi faktor yang menyebabkan adanya perbedaan angka prevalensi parasit saluran pencernaan karena ketahanan tubuh kucing terhadap suhu ekstrim terbatas (Puspita, 2013). Pada penelitian Pereira dkk. (2017) di Rio de Janeiro, Brazil menggunakan sampel 91 sampel feses kucing didapatkan prevalensi parasit saluran pencernaan sebesar 49,5\%. Angka prevalensi tersebut memiliki jumlah angka yang tidak jauh berbeda, hal tersebut kemungkinan dikarenakan di Rio de Janeiro dan di Surabaya yang memiliki wilayah geografis yang tidak jauh berbeda.

Tabel 1. Prevalensi Parasit Saluran Pencernaan Pada Kucing Yang Terdapat di Shelter Surabaya Timur

\begin{tabular}{lcc}
\hline \multirow{2}{*}{ Tempat } & \multicolumn{2}{c}{ Hasil } \\
\cline { 2 - 3 } Griya Satwa & Positif & Negatif \\
\cline { 2 - 3 } Kiro Cat & 19 & 31 \\
\hline Total & $36(43,9 \%)$ & $56(56,1 \%)$
\end{tabular}

Prevalensi parasit saluran pencernaan pada kucing berdasarkan tempat pengambilan feses dapat dilihat pada Tabel 2. di Shelter Griya Satwa ditemukan Isospora felis sebesar 5 sampel positif dari 45 sampel yang diamati atau 11,11\%, Ancylostoma sp. sebesar 6 sampel positif dari 45 sampel yang diamati atau 13,33\%, Toxocara cati sebesar 3 sampel positif dari 45 sampel yang diamati atau $6,66 \%$ dan Toxocara leonina sebesar 5 sampel positif dari 45 yang diamati atau $11,11 \%$. Sedangkan di shelter Ciro Cat didapatkan Isospora felis sebesar 6 sampel positif dari 37 sampel yang diamati atau 16,21\%, Ancylostoma sp. sebesar 5 sampel positif dari 37 sampel yang diamati atau $13,51 \%$, Toxocara cati sebesar 2 sampel positif dari 37 sampel yang diamati atau 5,45\% dan Toxocara leonina sebesar 4 sampel positif dari 37 yang diamati atau 10,81\%. Kejadian tersebut dikarenakan beberapa kemungkinan ,yaitu karena sistem pemeliharaan kucing di shelter yang cenderung membebaskan kucing berkeliaran, pemberian makan ditempat yang kurang bersih seperti dilantai yang telah tercemar oleh feses kucing sehingga mudahnya penyebaran parasit saluran pencernaan. Pada umumnnya penularan parasit saluran pencernaan karena termakanya telur cacing dan protozoa pada fase ookista melalui makanan dan minuman yang tercemar parasit (Afiyah, 2015).

Tabel 2. Prevalensi Parasit Saluran Pencernaan Pada Kucing Berdasarkan Tempat Pengambilan Feses

\begin{tabular}{lcc}
\hline \multicolumn{1}{c}{ Jenis Parasit } & Shelter Griya Satwa & Shelter Kiro Cat \\
\hline Isospora sp. & $5 / 45(11,11)$ & $6 / 37(16,21)$ \\
Ancylostoma sp. & $6 / 45(13,33)$ & $5 / 37(13,51)$ \\
Toxocara cati & $3 / 45(6,66)$ & $2 / 37(5,45)$ \\
Toxocara leonina & $5 / 45(11,11)$ & $4 / 37(10,81)$ \\
\hline \multicolumn{1}{c}{ Total } & $19 / 45(42,22)$ & $17 / 37(45,94)$
\end{tabular}


Berdasarkan hasil analisis chi square prevalensi parasit saluran pencernaan kucing berdasarkan tempat pengambilan feses antara shelter griya satwa dan shelter kiro cat memperoleh hasil $(\mathrm{p}>\mathrm{o}, 05)$, menunjukan bahwa prevalensi parasit saluran pencernaan berdasarkan tempat pengambilan feses antara shelter griya satwa dan shelter kiro cat tidak memiliki perbedaan yang signifikan.

\section{Jenis-jenis Parasit Saluran Pencernaan pada Kucing yang Terdapat di Shelter Surabaya Timur \\ Berdasarkan hasil pengamatan dengan} Optilab dan pengukuran menggunakan aplikasi McMaster protozoa dan telur cacing yang ditemukan di saluran pencernaan kucing di shelter Surabaya dapat dideskripsikan sebagai berikut, Isospora felis pada gambar 1. mempunyai ukuran 35,7-36,7 x 28,5-33,6 $\mu \mathrm{m}$, berbentuk bulat sedikit oval, berdinding tipis dan halus yang terdiri satu lapis, mengandung dua sporokista dan tidak memiliki mikropil. Hal tersebut sesuai dengan yang diungkapkan Soulsby (1986) yang menyatakan bahwa ookista Isospora felis mempunyai ukuran 38-51 $\mu \mathrm{m}$ dan berbentuk oval, memiliki dinding yang halus, serta tidak tampak adanya mikropil, pada pewarnaan menggunakan metode asam kinyoun akan terlihat sedikit pink. Telur Ancylostoma sp. pada gambar 2. yang ditemukan mempunyai ukuran 33,5-36,3 x 55,2-58,1 $\mu \mathrm{m}$, berbentuk oval, berdinding tipis yang terdiri dari dua lapisan dan mengandung dua sampai delapan blastomer. Hal ini sesuai dengan Taylor dkk. (2016) menyatakan Ancylostoma sp. berbentuk oval, ukuran telurnya 56-75 x 34-47 $\mu \mathrm{m}$ dan mengandung dua sampai delapan blastomer. Telur Toxocara cati pada gambar 3. berukuran 64,9-65,6 x 60,7$63,3 \mu \mathrm{m}$, berbentuk agak bulat, mempunyai kulit yang sedikit berbintik-bintik, berwarna kecoklatan dan dikelilingi lapisan albumin yang tebal. Sesuai dengan Subekti dkk. (2016) bahwa diameter telur Toxocara cati 65-75 $\mu \mathrm{m}$, telur agak bulat dan mempunyai kulit yang sedikit berbintik-bintik. Telur Toxocara leonina pada gambar 4. memiliki ukuran 70,14-74,84 x 54,4144,69 $\mu \mathrm{m}$, berbentuk oval dan berdinding halus. Sesuai dengan Subekti dkk. (2016) telur berbentuk oval, memiliki dinding yang halus dan berukuran $75-85 \times 75 \mu \mathrm{m}$.

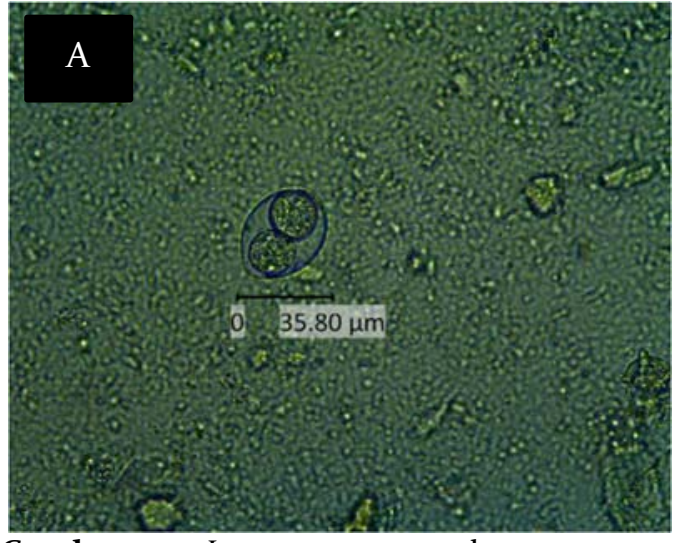

Gambar 1. Isospora sp. perbesaran 400x dengan metode natif.

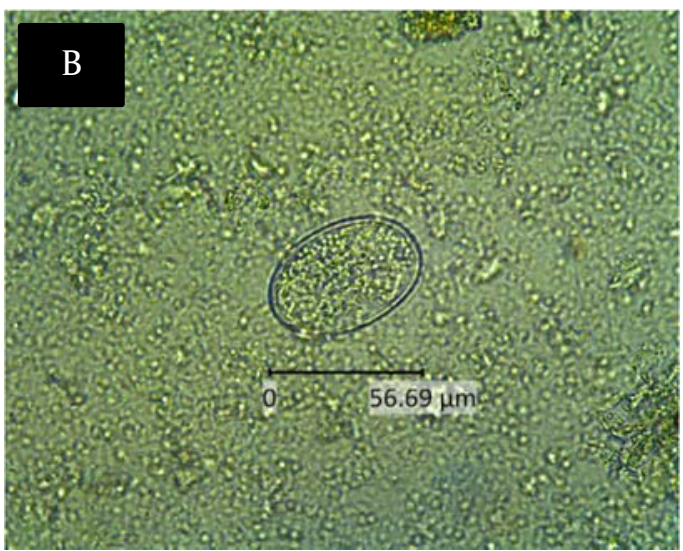

Gambar 2. Telur Ancylostoma sp. perbesaran 400x.

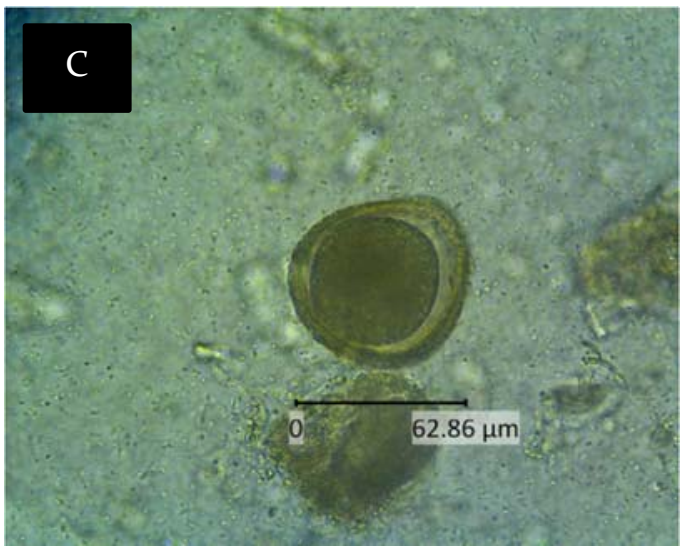

Gambar 3. Telur Toxocara cati perbesaran 400x. 


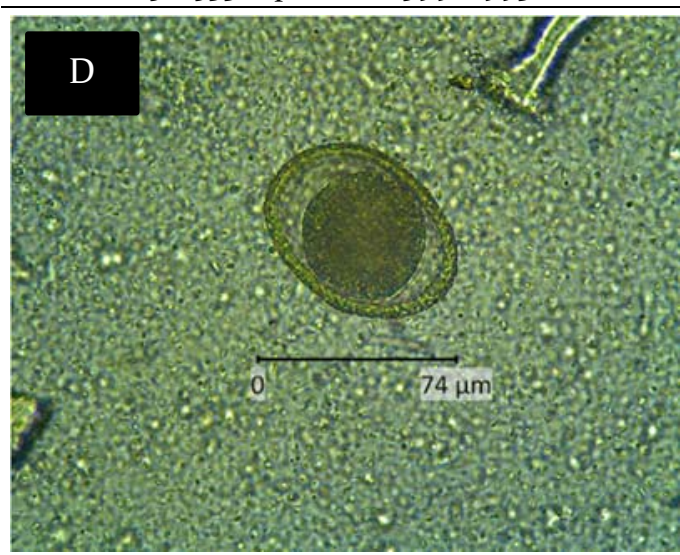

Gambar 4. Telur Toxocara leonine perbesaran 400x.

\section{Kesimpulan}

Angka prevalensi parasit saluran pencernaan pada kucing yang terdapat di shelter Surabaya adalah 43,9\%. Jenis parasit saluran pencernaan yang ditemukan menginfeksi kucing yang terdapat di shelter Surabaya antara lain protozoa Isospora sp., Telur Ancylostoma sp., telur Toxocara cati dan telur Toxocara leonina. Sistem pemeliharaan dan manajemen kebersihan kandang di shelter Surabaya Timur sangat berpengaruh terhadap besar angka prevalensi parasit. Kucing yang dipelihara secara bebas berkeliaran dan tidak diperhatikan kebersihan lingkungannya menjadi salah satu penyebab penularan parasit saluran pencernaan.

\section{Daftar Pustaka}

Afiyah, N. S. 2015. Deteksi Protozoa Saluran Pencernaan Pada Kucing Peliharaan di Kotamadya Surabaya. [SKRIPSI]. Fakultas Kedokteran Hewan. Universitas Airlangga. Surabaya.

Bowman, D. D., C. M. Hendrix,., D. S. Lindsay, S. C. Barr. 2002. The cestodes in Feline Clinical Parasitology. Iowa State University Press. 183-232

Gracenea, M. M. S. Gomez, J. Torres. 2009. Prevalence of Intestinal Parasites in Shelter Dogs and Cats in The Metropolitan Area of Barcelona. Stefanski Institute of Parasitology. 54 (1): 73-77

Hajipour, N., A. Baran, M. Yakhchali, S. M. B. Khjasteh, F. S. Hesari, B. Esmaeilnejad. 2016. A Survey Study On Gastrointestinal Parasites Of Stray Cats in Azarshahr. Iran. J. Parasit. 40 (4): 1255-1260
Joffe, D., D. V. Niekerk, F. Gagne, J. Gilleard, S. Kutz, R. Lobingier. 2011. The Prevalence of Intestinal Parasites in Dogs and Cats in Calgary, Alberta. Can Vet J. Calgary. (52) :1323-1328.

Levine, N. D. 1995. Buku Ajar Parasitologi Veteriner. Gadjah Mada Press. Yogyakarta.

Madyantari, N., S. Hidayat, T. Wahab. 2016. Perancangan Buku Ilustrasi Kucing di Bandung. E-Proceeding of Art \& Design. 3 (3): 746-753

Mumpuni, S., S. Subekti, S. Koesdarto, Puspitawati, H., dan Kusnoto. 2016. Penuntun Praktikum Ilmu Penyakit Helminth Veteriner. Fakultas Kedokteran Hewan Universitas Airlangga. Surabaya.

Murtidjo, B. A. 1994. Metode Riset Epidemiologi. Gadjah Mada University Press. Yogyakarta.

Nealma, S., I. M. Dwinata, I. B. M. Oka. 2013. Prevalensi Infeksi Cacing Toxocara cati pada Kucing Lokal di Wilayah Denpasar. Indonesia Medicus Veterinus. 2 (4): 428436

Pabundu, D. 2007. Kasus Penyakit Hewan di Rumah Sakit Hewan Pendidikan Fakultas Kedokteran Hewan Universitas Airlangga Periode 2003-2006 [SKRIPSI]. Fakultas Kedokteran Hewan Universitas Airlangga. Surabaya.

Pereira, P. F., A. D. S. Barbosa, A. P. P. D. Moura, M, L. Vasconcellos, C. M. A. Uchoa, O. M. P. Bastos, M. R. R. Amendoeira. 2017. Gastrointestinal parasites in stray and shelter cats in the municipality of Rio de Janeiro, Brazil. Braz. J. Vet. Parasitol. 26 (3): 383-388.

Raza, A., J. Rand, A. G. Qamar, A. Jabbarm S. Kopp. 2018. Gastrointestinal parasites in Shelter Dogs: Occurrence, Pathology, Treatment and Risk to Shelter Workers. Animals. 8 (108): 1-23

Soulsby, E. J. L. 1986. Helminths, Arthropods and Protozoa of Domestic Animals. 5 the Edition. The English Language Book Soc and Bailliere Tindall. London.

Subekti, S., S Mumpuni, S Koesdarto, S Puspitawati, dan Kusnoto. 2016. Buku Ajar Helmintologi Veteriner. Airlangga University Press. Surabaya. 
Sucitrayani, P. T. E., I. B. M. Oka, M. Dwinata. 2014. Prevalensi Infeksi Protozoa Saluran Pencernaan Pada Kucing Lokal (Felis catus) Di Denpasar. Buletin Veteriner Udayana. 8 (108): 1-23

Sulaiman. 2010. Berbisnis Pembibit Kucing. Lily Publisher. Yogyakarta.

Taylor, M. A., R. L. Coop, R. L. Wall. 2016. Veterinary Parasitology. $4^{\text {th }}$ Ed. United Kingdom. Blackwell Publising Ltd.
Tradana, M., D. T. Ardianto, Erandaru. 2011. Penggunaan Video Profile Sebagai Penyampaian Pemirsa: Studi Kasus Surabaya Animal Care Cummunity. Fakultas Seni dan Desain Universitas Kristen Petra Surabaya. 1-9 